\title{
Extracción dentaria como tratamiento de estomatitis linfocítica plasmocítica felina
}

\author{
Karen L. Vega-Benavides ${ }^{1} \bowtie$
}

1 Hospital Especies Menores y Silvestres, Escuela Medicina Veterinaria, Universidad Nacional

La estomatitis linfocítica plasmocítica es una enfermedad común en los gatos, considerada de fisiopatología inmunitaria por la gran cantidad de células plasmáticas presentes. Su presentación puede ser leve, con presencia de línea inflamatoria en zona gingival, hasta más severa con hemorragias en la encía y orofaringe, siendo más frecuentes las lesiones en los dientes caudales (molares y premorales); otros signos asociados son mucho dolor en la boca, molestia al comer, halitosis, pérdida de peso, ptialismo e inflamación generalizada en cavidad oral caudal.

Se pretende educar respecto a la patología, diagnóstico, abordaje y su debido tratamiento: algunos casos muestran mejoría transitoria con antibiótico y antinflamatorio esteroideo, sin embargo, la mayoría recae, hasta requerir la extracción dentaria radical, esta última, conocida como el tratamiento con mayor efectividad. Felino sin raza definida, macho, adulto. En el motivo de consulta reportan pérdida de peso, molestia en la cara y sangrado por boca. Como alteración en examen físico se encuentra condición corporal 2/5, halitosis, una marcada hiperplasia de tejido y ulceraciones en el nivel oral caudal, con marcada línea gingival inflamada y sangrante. Se procede a realizar biopsia y se confirma hallazgos compatibles con "gingivitis linfo-histio-plasmocitaria, o estomatitis caudal de etiología inmunomediada”. Se descartó hipertiroidismo, y concomitancia con VIFe y VLFe.

Se decide iniciar terapia médica con antibiótico (metronidazol y espiramicina) y corticoesteroides (Prednisolona), a dicho tratamiento el paciente tubo una mejoría moderada y transitoria; se recomienda extracción dentaria total (con la raíz de la pieza dental), a lo cual los propietarios deciden buscar una segunda opinión. Después de intentar tres ciclos más de tratamiento médico, en otros centros veterinarios, regresan a consulta con el paciente. El paciente es valorado, se envían hemograma y químicas sanguíneas, las cuales no presentaron alteración.

Se realiza la extracción desde la raíz de todas las piezas dentales, debido a la presentación severa del cuadro del paciente, se colocó sonda de alimentación esófago-gástrica y se mantuvo con terapia multimodal para manejo del dolor. Al quinto día el paciente empezó a comer dieta blanda por sí solo, se mantuvo dieta blanda sin problema. El paciente se recuperó en cuanto a síntomas y ganancia de peso, al mes posterior a la intervención quirúrgica. Contrario al temor de los propietarios, no alteró su calidad de vida, si no por el contrario, mejoró su ánimo, se dejaba acariciar y ganó peso. Se debe tener la estomatitis linfocítica plasmocítica como diagnóstico diferencial en enfermedades bucales felinas, sea con lesiones leves o severas. Además de no negarse a terapias más radicales, que si bien es cierto no tienen garantía en cuanto a la respuesta individual de cada paciente, pueden brindar mayor beneficio para ellos. Se puede iniciar terapia médica, pero a su vez estar pendiente de cuándo estas ya no son suficientes para el manejo adecuado de la enfermedad, y por ende para mejorar la calidad de vida del paciente.

凶 Autor para correspondencia Karen L. Vega-Benavides: karenluvega@hotmail.com 